\title{
Efeito alelopático do óleo essencial de Cymbopogon nardus e extrato de Annona muricata na germinação de Bidens pilosa e Megathyrsus maximus
}

\author{
Allelopathic effect of the essential oil of Cymbopogon nardus and Annona \\ muricata extract on the germination of Bidens pilosa and Megathyrsus maximus
}

\author{
Daniely Bindaco Hirata1,*, Ana Caroline Carvalho da Luz ${ }^{1}$, Leonardo Valandro Zanetti ${ }^{1}$, \\ Elias Terra Werner ${ }^{2}$, Camilla Rozindo Dias Milanez ${ }^{1}$ e Idalina Tereza de Almeida Leite ${ }^{1}$ \\ 1 Universidade Federal do Espírito Santo, Centro de Ciências Humanas e Naturais, Avenida Fernando Ferrari, n0 514, Goiabeiras, CEP 29075-910, Vitória, ES, Brasil \\ 2 Universidade Federal do Espírito Santo, Centro de Ciências Exatas, Naturais e da Saúde, Alto Universitário, caixa postal 16, s/n, CEP 29500-000, Alegre, ES, Brasil \\ ( ${ }^{\star} E$-mail: daniely.hirata@gmail.com) \\ http://dx.doi.org/10.19084/RCA17317
}

Recebido/received: 2017.12 .10

Recebido em versão revista/received in revised form: 2018.04 .05

Aceite/accepted: 2018.05 .09

\section{R E S U M O}

O objetivo deste trabalho foi verificar o efeito alelopático do óleo essencial de citronela (Cymbopogon nardus) e de extrato foliar de graviola (Annona muricata) na germinação de sementes de picão-preto (Bidens pilosa) e capim-colonião (Megathyrsus maximus). Utilizou-se como tratamentos: óleo essencial de citronela em diferentes concentrações: 0,25, 0,5, 1,0 e 1,5 mL/L (v/v) e extratos aquosos de graviola diluídos nas concentrações de 25, 50, 75 e 100\% (v/v), sendo utilizada água destilada como grupo controle. O delineamento experimental foi o inteiramente casualizado, sendo realizada uma Regressão na Análise de Variância na estatística. Os parâmetros avaliados foram: frequência relativa da germinação, porcentagem de germinação, tempo médio de germinação, velocidade média de germinação e índice de velocidade de germinação. Com o aumento das concentrações de óleo citronela, verificou-se efeito alelopático em todos os parâmetros analisados para as sementes de picão-preto e capim-colonião. As maiores concentrações de extrato de graviola interferiram em todos os parâmetros tanto para o picão-preto como para o capim-colonião.

Palavras-chave: plantas daninhas, sementes, alelopatia, herbicidas, manejo

\section{A B S T R A C T}

The objective of this work was to verify the allelopathic effect of the essential oil of citronella (Cymbopogon nardus) and soursop leaf extract (Annona muricata) on the germination of beggartick's (Bidens pilosa) and Guinea grass' seeds (Megathyrsus maximus). The treatments were: citronella essential oil at the following concentrations: $0.25,0.5,1.0$ and $1.5 \mathrm{~mL} / \mathrm{L}(\mathrm{v} / \mathrm{v})$ and aqueous soursop extracts at concentrations of 25, 50, 75 and $100 \% \mathrm{v} / \mathrm{v})$, and a control group of distilled water. The experimental design was completely randomized, and the statistical analysis were ran with a Regression in Analysis of Variance. The parameters evaluated were: relative germination frequency, percentage of germination, average germination time, average germination speed and germination speed index. The results showed that citronella oil was effective in all concentrations: the higher the concentration, the higher was the effect on beggartick and Guinea grass seed germination. The highest concentrations of soursop extract interfered in the all the parameters of beggartick as well as in Guinea grass.

Keywords: weeds, seeds, allelopathy, herbicides, management 


\section{INTRODUÇÃO}

Plantas daninhas podem ser definidas como todo e qualquer vegetal que se desenvolve em locais não desejados, consideradas exóticas e causadoras de impactos, principalmente em plantas cultivadas (Shaw, 1982). Dentre esses impactos destacam-se o aumento nos custos da produção em lavouras, danos na eficiência da terra e no controle de doenças e pragas (Ashton \& Monaco, 1991).

Dentre as espécies que interferem nas produções agrícolas, destaca-se o picão-preto (Bidens pilosa L.), pertencente à família Asteraceae, que apresenta grandes estratégias de sobrevivência, tais como produção de aquênios de fácil dispersão, resistência ao estresse hídrico, nutricional e luminoso, características estas que lhe conferem uma alta plasticidade fenotípica (Kissmann \& Groth, 2000). Megathyrsus maximus (Jacq.) BK Simon \& SWL Jacobs) (Holm et al., 1991), conhecido vulgarmente como capim-colonião, também se destaca como uma daninha que interfere nos cultivos agrícolas, por ser uma gramínea vigorosa, com grande capacidade de ocupar diversos ambientes rapidamente, sejam terrenos baldios ou em culturas de outras espécies, Portanto é também considerada uma espécie altamente competitiva (Lorenzi, 2008).

Atualmente o combate a estas plantas é realizado utilizando-se defensivos agrícolas. Contudo, apesar da eficiência dessa técnica, essa prática traz sérias consequências ambientais por não atender às exigências em relação à preservação da qualidade dos alimentos e dos recursos naturais. Neste contexto, a alelopatia tem se mostrado um meio promissor para o manejo mais adequado das plantas infestantes, por aliar sustentabilidade e produtividade (Mano, 2004). Alelopatia é definida como o efeito benéfico ou inibitório que os produtos do metabolismo secundário da planta, ao serem lançados no meio, podem causar sobre outros organismos (Rice, 1984; Ferreira \& Borghetti, 2004). Os produtos do metabolismo secundário funcionam como aleloquímicos, biomoléculas encontradas naturalmente nas plantas, que estão relacionadas a mecanismos de defesa bióticos e abióticos (Einhellig, 1999; Waller, 1999; Ferreira \& Aquila, 2000; Reigosa et al., 2013), e geralmente são enquadradas nos grupos dos ácidos fenólicos, terpenoides, etileno, taninos, alcaloides, entre outros (Medeiros, 1990).

Entre as espécies que podem contribuir para o controle biológico através de seus aleloquímicos, destacam-se o capim citronela (Cymbopogon nardus (L.) Rendle) e a graviola (Annona muricata L.). O capim citronela é uma espécie medicinal e aromática, pertencente à família Poaceae, cujo cultivo no Brasil tem crescido devido à procura pelo seu óleo essencial, utilizado para a fabricação de repelentes. O óleo é composto por diversas substâncias, sendo o citronelal e geraniol encontrados em maior abundância (Rocha et al., 2000; Aguiar-Menezes, 2005; Furtado et al., 2005). A graviola, espécie da família Annonaceae, é apreciada economicamente na indústria de sucos e polpas e pelo uso medicinal, devido às suas propriedades antiparasitária, antimicrobiana, inseticida, antiespasmódica e antidiabética (Sahpaz et al., 1994; Badrie \& Schauss, 2010; Florence et al., 2014). Tais atividades estão relacionadas à produção de metabólitos secundários, como alcaloides, acetogeninas e flavonoides (Alali et al., 1999; Bermejo et al., 2005). De acordo com Carvalho et al. (1996), estudos relacionados às substâncias alelopáticas que visam identificar plantas com aleloquímicos capazes de influenciar o desenvolvimento de plantas invasoras são de grande relevância. Nesse sentido, o objetivo do presente trabalho foi avaliar o potencial alelopático de diferentes concentrações de óleo essencial de citronela e de extrato aquoso foliar de graviola sobre a germinação de sementes de picão-preto e de capim-colonião.

\section{MATERIAL E MÉTODOS}

\section{Delineamento experimental e material vegetal}

O experimento foi realizado no Laboratório de Sementes e Ecofisiologia Florestal (LASEF) do Departamento de Ciências Biológicas, Universidade Federal do Espírito Santo, no período de outubro de 2013 a março de 2014. Os ensaios foram montados no delineamento inteiramente casualizado, onde foram testados 10 tratamentos, sendo 5 tratamentos referentes ao óleo de citronela e 5 tratamentos referentes ao extrato aquoso de graviola, para picão-preto e capim-colonião, com cinco repetições cada, em placas de Petri contendo 25 sementes por repetição. 
As sementes de picão-preto foram obtidas em campo, no município de Iconha (Estado do Espírito Santo) e as sementes de capim-colonião foram obtidas comercialmente, ambas foram armazenadas em local refrigerado.

\section{Preparo de extratos e de óleos essenciais}

Para o preparo dos tratamentos com citronela, utilizou-se óleo essencial comercial, com $70 \%$ de pureza, sendo emulsionado com Tween 80, na proporção 1:1 (v/v). A solução foi diluída com água destilada em diferentes concentrações: $0,0 \mathrm{~mL} / \mathrm{L}$ (controle), 0,25 mL/L, 0,5 mL/L, 1,0 mL/L e 1,5 mL/L. O material botânico utilizado para os extratos aquosos vegetais foi folhas recém coletadas de graviola, obtidas no campus da Universidade Federal do Espírito Santo (UFES).

O extrato aquoso vegetal foi obtido por meio de infusão de folhas frescas e rasuradas, imersas em água destilada a $90^{\circ} \mathrm{C}$, na proporção de $200 \mathrm{~g}$ de massa fresca para $1 \mathrm{~L}$ de água destilada. Após atingir a temperatura ambiente $\left(25^{\circ} \mathrm{C}\right)$, o extrato foi filtrado e posteriormente realizada sua diluição com água destilada para se obter diferentes concentrações: $0 \%$ (controle, água destilada), 25\%, $50 \%, 75 \%$ e $100 \%$ do extrato bruto.

\section{Ensaios de alelopatia}

Para os bioensaios de germinação, foram utilizadas placas de Petri $(9 \mathrm{~cm})$ forradas com dois discos de papel filtro, previamente autoclavadas a $120{ }^{\circ} \mathrm{C}$, pressão de $1 \mathrm{kgf} / \mathrm{cm}^{2}$ durante 30 minutos. Distribuiu-se 25 sementes de mesmo tamanho de picão-preto e capim-colonião por placa, previamente desinfestadas com Captan 0,5\%. As placas foram umedecidas com volume padronizado de $5 \mathrm{~mL} / \mathrm{L}$ para cada tratamento, sendo mantidos em câmara de germinação à temperatura de $25{ }^{\circ} \mathrm{C}$ $\left( \pm 1{ }^{\circ} \mathrm{C}\right)$ e fotoperíodo de 12 horas. Realizou-se monitoramento diário do experimento, sendo consideradas germinadas as sementes que apresentaram radículas maiores ou iguais à $2 \mathrm{~mm}$ de comprimento (Brasil, 1992). Determinou-se o fim do experimento após três dias de monitoramento sem nenhuma ocorrência de germinação.
Foram avaliados os seguintes parâmetros: frequência relativa da germinação (FR), porcentagem de germinação (\%), tempo médio de germinação, velocidade média de germinação e índice de velocidade de germinação (IVG), com a seguinte fórmula, proposta por Maguire (1962): $\Sigma$ (G1 / N1) + (G2 / N2 + ... + Gn / Nn), onde "G" é o número de sementes germinadas e «N» representa o tempo após a semeadura.

\section{Análise estatística}

Os dados foram submetidos à Regressão na Análise de Variância (ANOVA) e ao teste de Tukey ( $p$-valor $<0.05)$ para comparação de médias. Todas as análises foram realizadas com auxílio do software estatístico Assistat versão 7.7.

\section{RESULTADOS E DISCUSSÃO}

As soluções provenientes do óleo essencial de citronela e suas respectivas diluições alteraram o comportamento da germinação das sementes de picão-preto e de capim-colonião. Os gráficos de frequência relativa da germinação (Figura 1) mostram o comportamento da germinação durante o período do experimento. Observou-se que as maiores concentrações acarretaram atrasos no início da germinação de ambas as espécies (Figura 1). No picão-preto, a germinação iniciou-se após três dias, tratamento controle, enquanto que na maior concentração do óleo essencial $(1,5 \mathrm{~mL} / \mathrm{L})$ as sementes germinaram a partir do décimo terceiro dia de incubação (Figura 1). Comportamento semelhante foi observado para as sementes de capim-colonião, que germinaram no segundo dia no tratamento controle, e para a concentração de $1,5 \mathrm{~mL} / \mathrm{L}$, no décimo quarto dia (Figura 1). Extratos que apresentam maiores concentrações tendem a atuar de maneira a inibir ou retardar o início da germinação (Rizzardi et al., 2008; Azambuja et al., 2010; Alves et al., 2011), eventualmente tornando as sementes inviáveis (Petersen et al., 2001) devido a ação dos aleloquímicos que interferem tanto no metabolismo da germinação (Bewley \& Black, 1994) quanto no desenvolvimento inicial da plântula (Rizzardi et al., 2008). Em relação à porcentagem de germinação, as maiores concentrações do 
óleo de citronela acarretaram uma maior inibição da germinação das sementes de picão-preto (Figura 2). Segundo Ferreira \& Borghetti (2004), nem sempre o potencial alelopático é evidenciado diretamente pela porcentagem de germinação, sendo importante avaliar outros fatores aliados ao comportamento germinativo, tais como: tempo médio de germinação, velocidade média de germinação e o índice de velocidade de germinação. Nos presentes resultados, esses parâmetros apresentaram, nas maiores concentrações, atraso no início da germinação e baixa velocidade de germinação nas sementes de picão-preto, quando comparadas com o tratamento controle (Figura 2).

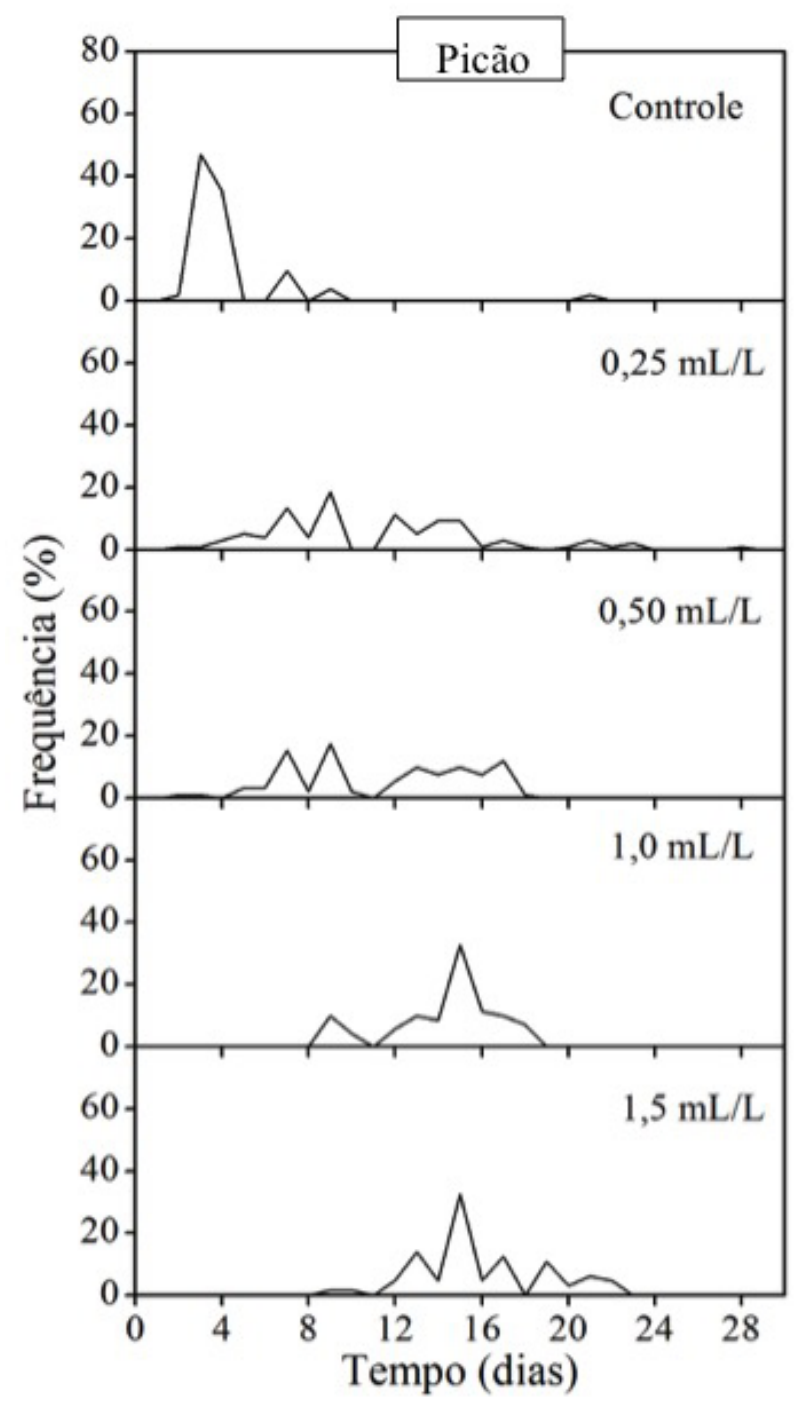

O óleo de citronela também reduziu e retardou a germinação das sementes de capim-colonião com o aumento das concentrações (Figura 3). O efeito alelopático é relatado na literatura tanto com o aumento da concentração (Gusman et al., 2008), quanto em menores concentrações (PiñaRodrigues \& Lopes, 2001). Este efeito variável em função da concentração utilizada se dá pela existência de uma especificidade entre a planta receptora e a planta doadora dos extratos (Souza Filho et al., 1997). Aliada a isso, a potencialidade alelopática dos extratos é citada na literatura como resultado da composição majoritária de aleloquímicos presentes nos extratos utilizados (Souza Filho

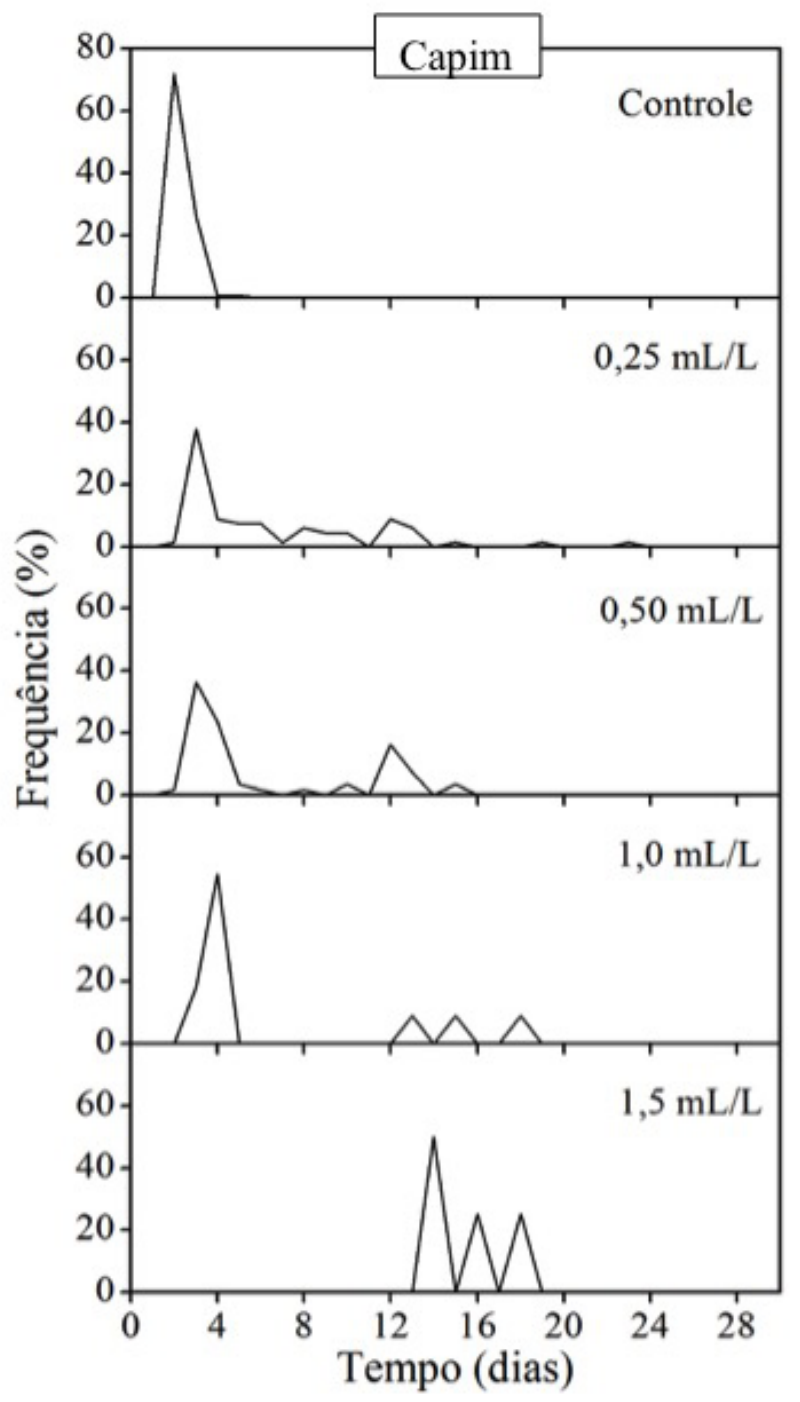

Figura 1 - Frequência relativa (\%) de germinação de sementes de picão-preto e capim-colonião sob diferentes concentrações de óleo essencial de citronela. 

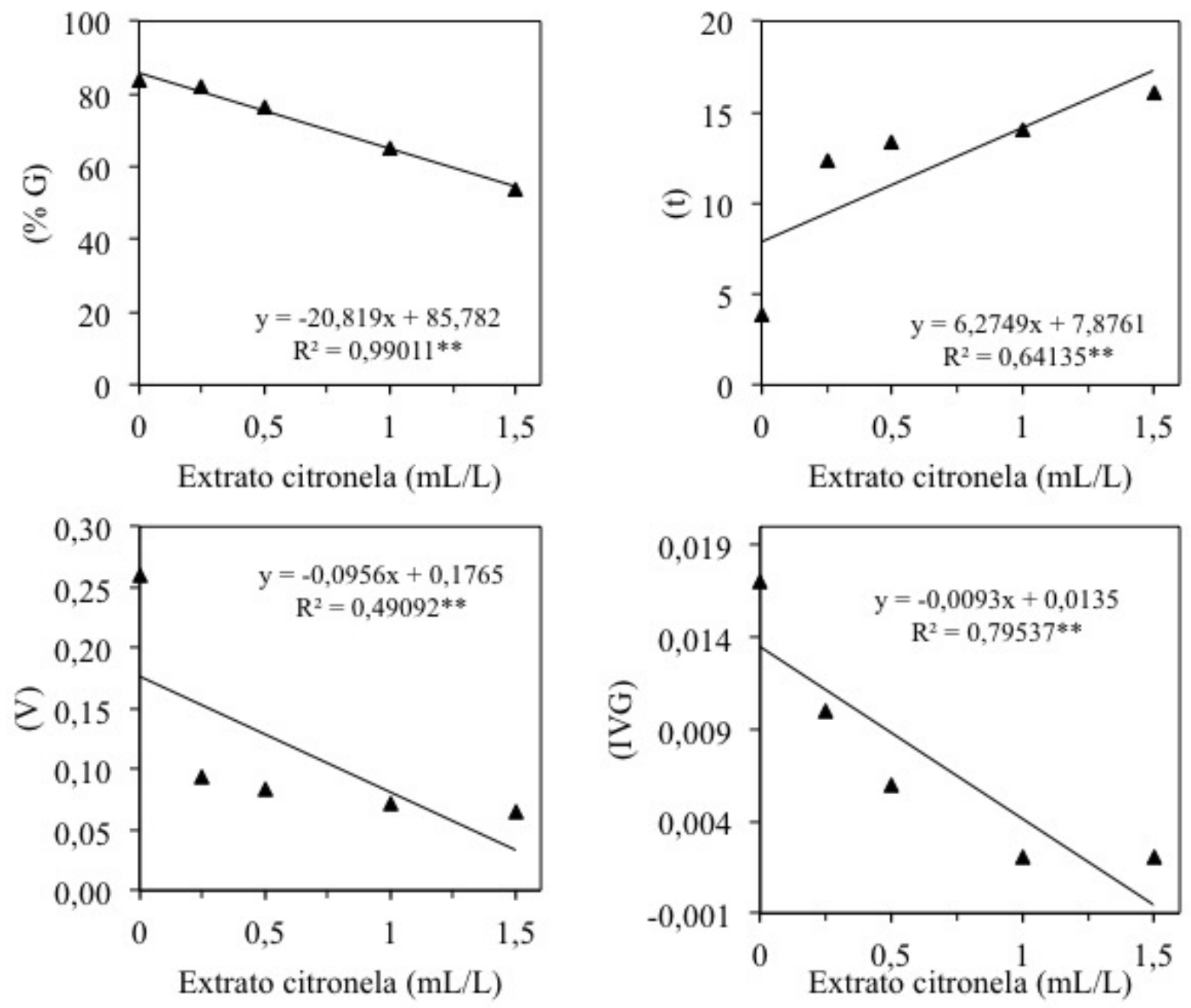

Figura 2 - Efeito alelopático de diferentes concentrações de óleo essencial de citronela sobre sementes de picão-preto na porcentagem de germinação $(\% G)$, tempo médio de germinação $(t)$, velocidade média de germinação $(V)$ e índice de velocidade de germinação (IVG). ** significativo ao nível de $1 \%$ de probabilidade $(p<.01)$.

et al., 2009; Miranda et al., 2015a,b), sendo neste caso, representada pela classe química dos monoterpenos em óleo de citronela, dentre eles o citronelal (Matos, 2000). Há registros na literatura de que esses compostos químicos apresentam potencial alelopático sobre a germinação de sementes (Alves et al., 2004; Corsato et al., 2010; Pereira et al., 2014), ocasiona redução na velocidade de germinação (Gatti et al., 2004; Rosa et al., 2007), murcha, necrose, redução da parte aérea e do acúmulo de massa seca (Brito et al., 2012). Os aleloquímicos podem afetar diversos processos fisiológicos em plantas, tais como germinação das sementes, assimilação de nutrientes, crescimento das plântulas, fotossíntese, síntese protéica, respiração, atividade de diversas enzimas, além da perda de nutrientes pelos efeitos na permeabilidade da membrana celular (Rodrigues et al., 1993; Einhellig, 1995).

As sementes de picão-preto testadas com as diferentes concentrações de extrato de graviola apresentaram comportamento germinativo retardado quando comparadas às sementes do tratamento controle (Figura 4). Nas concentrações testadas, as sementes iniciaram sua germinação entre o terceiro e quarto dia, no entanto, na maior concentração um maior número de sementes germinadas foi observado ao oitavo dia. Sementes de capim-colonião 

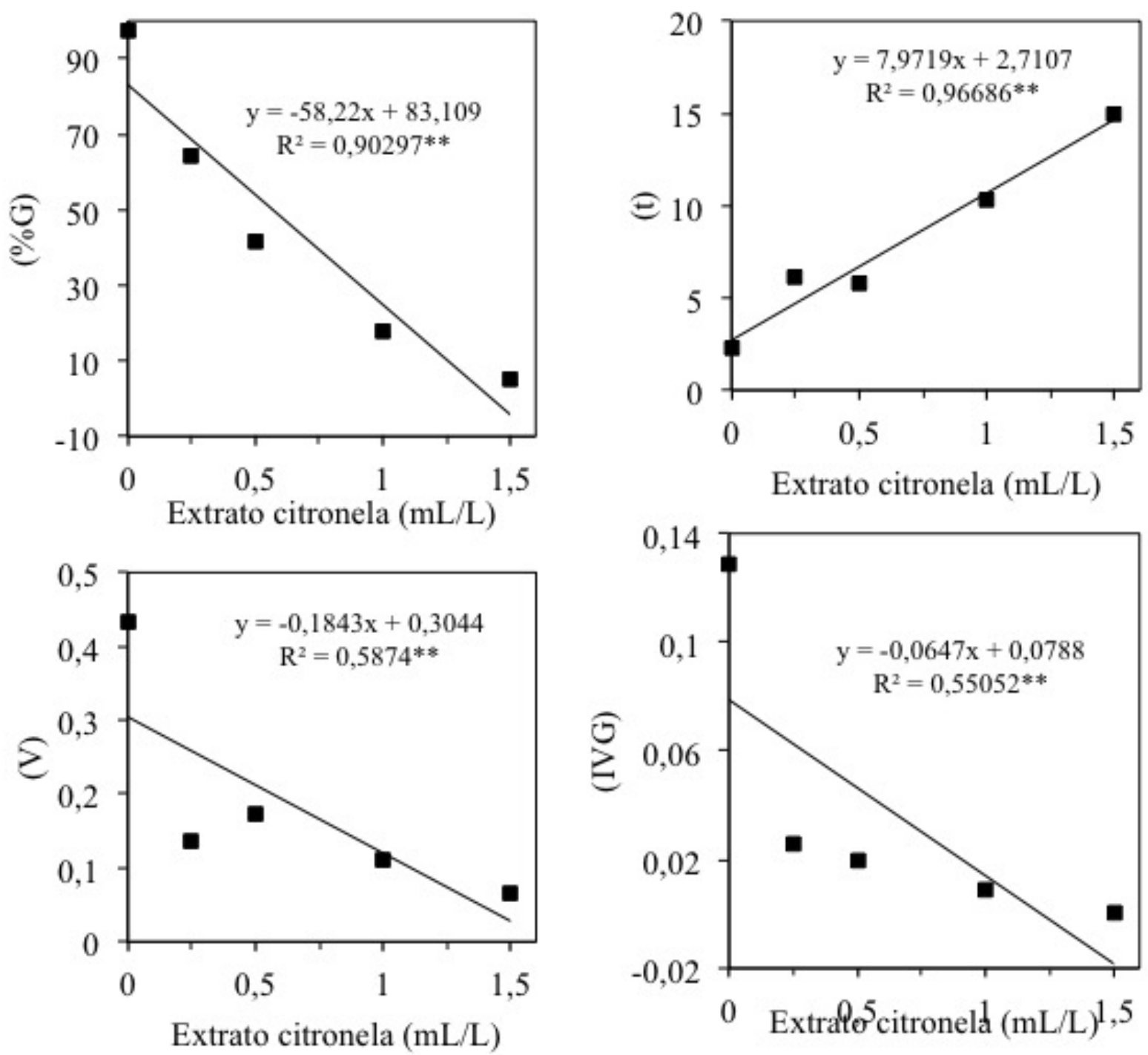

Figura 3 - Efeito alelopático de diferentes concentrações de óleo essencial de citronela sobre sementes de capim-colonião na porcentagem de germinação (\%G), tempo médio de germinação $(\mathrm{t})$, velocidade média de germinação $(\mathrm{V})$ e índice de velocidade de germinação (IVG). ${ }^{* *}$ significativo ao nível de $1 \%$ de probabilidade ( $\left.p<.01\right)$.

submetidas ao extrato de graviola em maiores concentrações também apresentaram um atraso na germinação em relação ao controle (Figura 4). Esse atraso é corroborado pelo tempo médio de germinação, velocidade média de germinação e índice de velocidade de germinação quando comparadas ao tratamento controle (Figura 5). Alterações na velocidade de germinação podem ter consequências ecológicas significativas, uma vez que o tempo de germinação é um fator determinante para a sobrevivência das plântulas, refletindo sobre o crescimento e atuação nos estágios subsequentes do desenvolvimento (Fenner, 2000). Sementes que germinam mais lentamente podem dar origem a plântulas com tamanho reduzido, interferindo assim no processo de competição por recursos e se tornando mais suscetíveis a estresses e predação, apresentando menor chance de sobrevivência (Jefferson \& Pennachio, 2003).

Em picão-preto, o parâmetro porcentagem de germinação foi influenciado pelo extrato de 

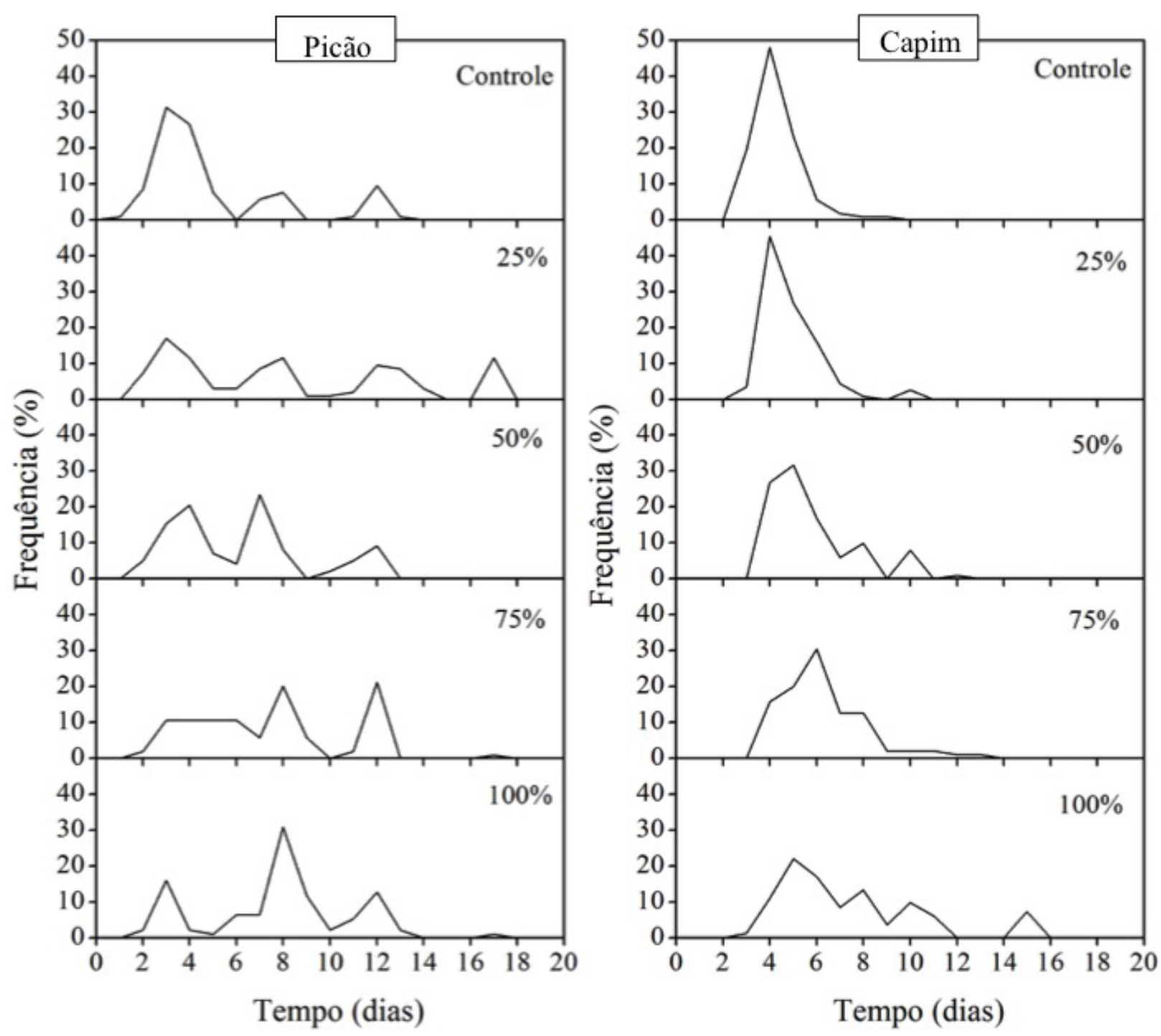

Figura 4 - Frequência relativa (\%) de germinação de sementes de picão-preto e capim-colonião sob diferentes concentrações de extrato aquoso foliar de graviola.

graviola à medida que a concentração aumentou (Figura 5). Apesar de a germinação ser considerada menos sensível aos aleloquímicos do que o desenvolvimento e crescimento inicial das plântulas (Ferreira \& Borghetti, 2004), estudos realizados com extrato de Mikania micrantha em sementes de Coix lacryma-jobi (Li \& Jin, 2010) e de Xanthium strumarium em sementes de Lens culinaris encontraram menores porcentagens de germinação em concentrações maiores, ocasionando atraso na emergência de plântulas (Benyas et al., 2010).
Quanto aos parâmetros avaliados, as sementes de capim-colonião apresentaram sensibilidade ao extrato de graviola com o aumento da concentração (Figura 6). A classe química das acetogeninas é predominante na família Annonaceae e caracteriza-se por apresentar propriedades citotóxicas, sendo considerada uma nova classe de pesticidas naturais (Badrie \& Schauss, 2010). Por apresentarem atividade biológica, pode-se inferir que esses mesmos compostos também possam interferir na germinação das sementes de capim-colonião, 

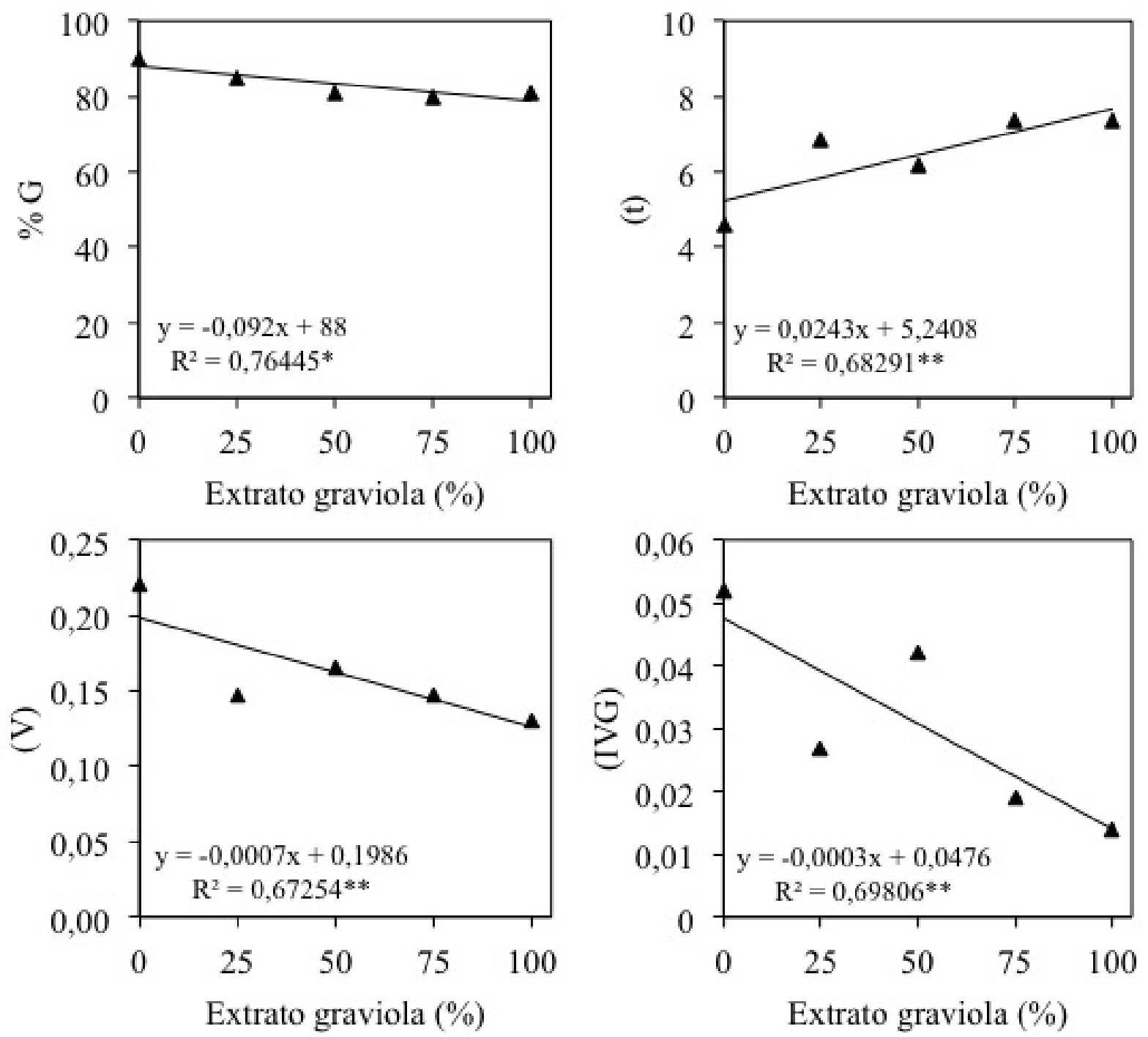

Figura 5 - Efeito alelopático de diferentes concentrações de extrato aquoso de graviola sobre sementes de picão-preto na porcentagem de germinação (\%G), tempo médio de germinação (t), velocidade média de germinação (V) e índice de velocidade de germinação (IVG). * significativo ao nível de $5 \%$ de probabilidade ( $p<.05)$; ** significativo ao nível de $1 \%$ de probabilidade $(p<.01)$.

através de desestabilização das membranas celulares, e alterações na síntese de DNA (Ferreira \& Borghetti, 2004), servindo como uma alternativa para controle de plantas invasoras em cultivos, de forma sustentável.

Para tanto, é de suma importância à realização de estudos futuros que visam conhecer a natureza química dos diferentes aleloquímicos dos extratos testados. Assim como estudos que relacionem a bioatividade dos extratos testados no desenvolvimento inicial de plântulas, evidenciando as possíveis alterações morfo-anatômicas em raízes e órgãos fotossintetizantes de picão-preto e capim-colonião, sejam em condições de laboratório ou de campo. Estudos de campo são muito importantes, uma vez que visa à utilização desses extratos em cultivos orgânicos e agroflorestais em substituição à utilização de herbicidas sintéticos. 

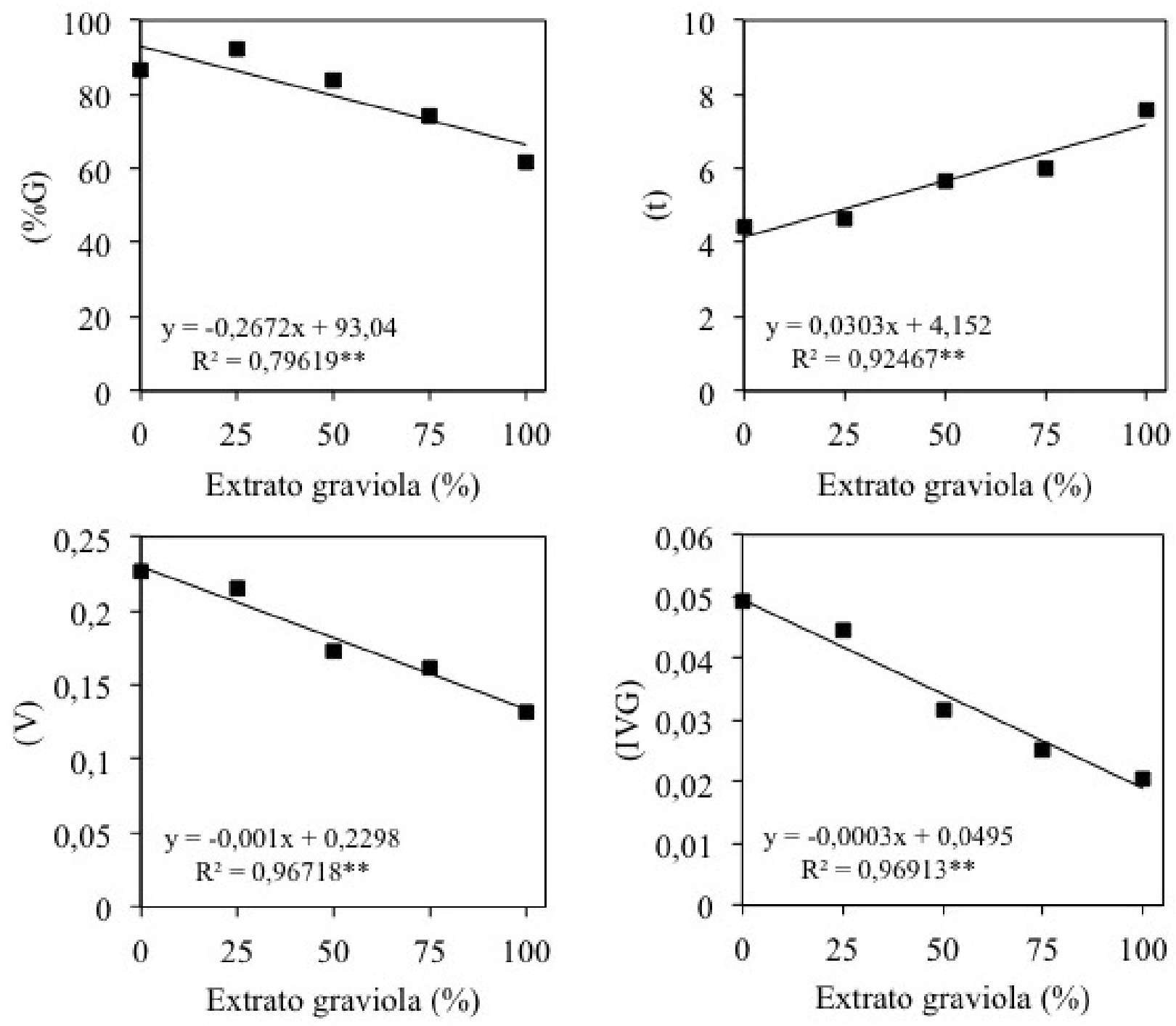

Figura 6 - Efeito alelopático de diferentes concentrações de extrato aquoso de graviola sobre sementes de capim-colonião na porcentagem de germinação (\%G), tempo médio de germinação (t), velocidade média de germinação $(V)$ e índice de velocidade de germinação (IVG). ** significativo ao nível de $1 \%$ de probabilidade $(p<.01)$.

\section{CONCLUSÕES}

Os extratos de óleo essencial de citronela apresentaram efeitos alelopáticos nas sementes de picão-preto e capim-colonião nas maiores concentrações para todos os parâmetros avaliados.

Os extratos aquosos de folhas de graviola foram efetivos na redução da porcentagem de germinação e no atraso da germinação de picão-preto.
Os extratos aquosos de folhas de graviola apresentaram efeitos alelopáticos em todos os parâmetros testados para as sementes de capim-colonião.

\section{AGRADECIMENTOS}

À Universidade Federal do Espírito Santo pela concessão da bolsa de Iniciação Científica. 


\section{REFERÊNCIAS BIBLIOGRÁFICAS}

Aguiar-Menezes, E. de L. (2005) - Inseticidas botânicos: seus princípios ativos, modo de ação e o uso agrícola. Embrapa Agrobiologia. 58 p.

Alali, F.Q.; Liu, X.X. \& McLaughlin, J.L. (1999) - Annonaceous acetogenins: recent progress. Journal of Natural Products, vol. 62, n. 3, p. 504-540. https://doi.org/10.1021/np980406d

Alves, M. da C. S.; Medeiros Filho, S.; Innecco, R. \& Torres, S.B. (2004) - Alelopatia de extratos voláteis na germinação de sementes e no comprimento da raiz de alface. Pesquisa Agropecuária Brasileira, vol.39, n. 11, p. 1083-1086. http://dx.doi.org/10.1590/S0100-204X2004001100005

Alves, L.L.; Oliveira, P.V.A.; França, S.C.; Alves, P.L.C. \& Pereira, P.S. (2011) - Atividade alelopática de extratos aquosos de plantas medicinais na germinação de Lactuca sativa L. e Bidens pilosa L. Revista Brasileira de Plantas Medicinais, vol. 13, n. 3, p. 328-336. http://dx.doi.org/10.1590/S1516-05722011000300012

Ashton, F.M. \& Monaco, T.J. (1991) - Weed science: principles \& practices. 3rd. ed. New York: John Wiley \& Sons, $466 \mathrm{p}$.

Azambuja, N.; Hoffmann, C.E.F.; Neves, L.A.S. \& Goulart, E.P.L. (2010) - Potencial alelopático de Plectranthus barbatus Andrews na germinação de sementes de Lactuca sativa L. e de Bidens pilosa L. Revista de Ciências Agroveterinárias, vol. 9, n. 1, p. 66-73.

Badrie, N. \& Schauss, A.G. (2010) - Soursop (Annona muricata L.): composition, nutritional value, medicinal uses, and toxicology. In: Bioactive Foods in Promoting Health, p. 621-643. Academic Press. https://doi.org/10.1016/ B978-0-12-374628-3.00039-6

Benyas, E.; Hassanpouraghdam, M.B.; Zehtab Salmasi, S. \& Khatamian Oskooei, O. S. (2010) - Allelopathic effects of Xanthium strumarium L. shoot aqueous extract on germination, seedling growth and chlorophyll content of lentil (Lens culinaris Medic.). Romanian Biotechnological Letters, vol. 15, n. 3, p. 5223-5228.

Bermejo, A.; Figadère, B.; Zafra-Polo, M.C.; Barrachina, I., Estornell, E. \& Cortes, D. (2005) - Acetogenins from Annonaceae: recent progress in isolation, synthesis and mechanisms of action. Natural Product Reports, vol. 22, n. 2, p. 269-303. https://doi.org/10.1039/b500186m

Bewley, J.D. \& Black, M. (1994) - Seeds: physiology of development and germination. 2.ed. New York: Plenum Press, $445 \mathrm{p}$.

Brasil (1992) - Regras de Análise de Sementes (RAS). Brasília: Ministério da Agricultura e Reforma Agrária, 365 p.

Brito, D.R.; Ootani, M.A.; Ramos, A.C.C.; Sertão, W.C. \& Souza Aguiar, R.W. (2012) - Efeito dos óleos de citronela, eucalipto e composto citronelal sobre micoflora e desenvolvimento de plantas de milho. Journal of Biotechnology and Biodiversity, vol. 3, n. 4, p. 184-192.

Carvalho, G.J.; Andrade, L.A.B.; Gomide, M. \& Figueiredo, P.A.M. (1996) - Potencialidades alelopáticas de folhas verdes mais ponteiros de cana-de-açúcar em diferentes concentrações de matéria seca, na germinação de sementes de alface. Ciências, vol. 5, n. 2, p. 19-24.

Corsato, J.M.; Fortes, A.M.T.; Santorum, M. \& Leszczynski, R. (2010) - Efeito alelopático do extrato aquoso de folhas de girassol sobre a germinação de soja e picão-preto. Semina: Ciências Agrárias, vol. 31, n. 2, p. 353-360.

Einhellig, F.A. (1995) - Plant x plant allelopathy: biosynthesis and mechanism of action. In: Congresso Brasileiro de Fisiologia Vegetal, Lavras. Anais. Lavras: UFLA, p. 59-74.

Einhellig, F.A. (1999) - An integrated view of allelochemicals amid multiple stresses. In: Inderjit; Dakshini, K.M.M.; Foy, C.L. (Eds.) - Principles and practices in plant ecology. Boca Raton: CRC Press, p.479-494.

Fenner, M. (2000) - Seeds: the ecology of regeneration in plant communities. Wallingford: CABI Publishing, p. 237-260.

Ferreira, A.G. \& Aquila, M.EA. (2000) - Alelopatia: uma área emergente da ecofisiologia. Revista Brasileira de Fisiologia Vegetal, vol. 12, n. 1, p. 175-204.

Ferreira, A.G. \& Borghetti, F. (2004) - Germinação: do básico ao aplicado. Porto Alegre: Artmed, p. 209-262.

Florence, N. T.; Benoit, M.Z.; Jonas, K.; Alexandra, T.; Désiré, D.D.P.; Pierre, K. \& Théophile, D. (2014) Antidiabetic and antioxidant effects of Annona muricata (Annonaceae), aqueous extract on streptozotocininduced diabetic rats. Journal of Ethnopharmacology, vol. 151, n. 2, p. 784-790. https://doi.org/10.1016/j. jep.2013.09.021 
Furtado, R.F.; Lima, M.G.A. ; Neto, M.A.; Bezerra, J.N.S. \& Silva, M.G.V. (2005) - Atividade larvicida de óleos essenciais contra Aedes aegypti L. (Diptera: Culicidae). Neotropical Entomology, vol. 34, n. 5, p. 843-847.

Gatti, A.B.; Perez, S.C.J.G.D. \& Lima, M.I.S. (2004) - Allelopathic activity of aqueous extracts of Aristolochia esperanzae O. Kuntze in the germination and growth of Lactuca sativa L. and Raphanus sativus L. Acta Botanica Brasilica, vol. 18, n. 3, p. 459-472. http://dx.doi.org/10.1590/50102-33062004000300006

Gusman, G.S.; Bittencourt, A.H.C. \& Vestena, S. (2008) - Alelopatia de Baccharis dracunculifolia DC. sobre a germinação e desenvolvimento de espécies cultivadas. Acta Scientiarum. Biological Sciences, vol. 30, n. 2, p. 119-125. http://dx.doi.org/10.4025/actascibiolsci.v30i2.3592

Holm, L.R.G.; Plucknett, D.L. \& Pancho, J.V. (1991) - The world's worst weeds: distribution and biology. Honolulu: East West Food Institute, $190 \mathrm{p}$.

Jefferson, L.V. \& Pennachio, M. (2003) - Allelopathic effects of foliage extracts from four Chenopodiaceae species on seed germination. Journal of Arid Environments, vol. 55, n. 2, p. 275-285. https://doi.org/10.1016/S01401963(03)00028-4

Kissmann, G. \& Groth, D. (2000) - Plantas infestantes e nocivas. 2. ed. São Paulo: BASF, 722 p.

Li, J. \& Jin, Z. (2010) - Potential allelopathic effects of Mikania micrantha on the seed germination and seedling growth of Coix lacryma-jobi. Weed Biology and Management, vol. 10, n. 3, p. 194-201. https://doi.org/10.1111/j.14456664.2010.00384.x

Lorenzi, H. (2008) - Plantas daninhas do Brasil: terrestres, aquáticas, parasitas e tóxicas. 4. ed. Nova Odessa: Editora Plantarum, $640 \mathrm{p}$.

Maguire, J.D. (1962) - Speed of germination-aid in selection and evaluation for seedling emergence and vigor. Crop Science, vol. 2, n. 2, p. 176-177.

Mano, A.R. de O. (2004) - Efeito alelopático do extrato aquoso de sementes de cumaru (Amburana cearensis S.) sobre a germinação de sementes, desenvolvimento e crescimento de plântulas de alface, picão-preto e carrapicho. Dissertação (Mestrado em Agronomia) - Universidade Federal do Ceará, Fortaleza.

Matos, F.J.A. (2000) - Plantas medicinais: guia de seleção e emprego de plantas usadas em fitoterapia no Nordeste do Brasil. 2.ed. Fortaleza: Imprensa Universária, 346p.

Medeiros, A.R.M. (1990) - Alelopatia: importância e suas implicações. Horti Sul, vol. 1, n. 3, p. 27-32.

Miranda, C.A.S.F.; Cardoso, M.G.; Carvalho, M.L.M.; Machado, S.M.F.; Gomes, M.D.; Santiago, J.A. \& Teixeira, M.L. (2015a) - Atividade alelopática de óleos essenciais de plantas medicinais na germinação e vigor de aquênios de alface. Semina: Ciências Agrárias, vol. 36, n. 3, p. 1783-1798. http://dx.doi.org/10.5433/16790359.2015v36n3Supl1p1783

Miranda, C.A.S.F.; Cardoso, M.G.; Carvalho, M.L.M.; Machado, S.M.F.; Andrade, M.A.; Oliveira, C.M. (2015b) - Análise comparativa do potencial alelopático do óleo essencial de Thymus vulgaris e seu constituinte majoritário na germinação e vigor de sementes de alface (Lactuca sativa L.). e-Xacta, vol. 8, n. 2, p. 45-53. http://dx.doi.org/10.18674/exacta.v8i2.1516

Pereira, V.C.; Grisi, P.U.; Dodonov, P.; Anese, S.; Toffano, L. \& Gualtieri, S.C.J. (2014) - Atividade fitotóxica de Serjania lethalis sobre a germinação e crescimento de Panicum maximum. Biotemas, vol. 27, n. 1, p. 29-35. https://doi.org/10.5007/2175-7925.2014v27n1p29

Petersen, J.; Belz, R.; Walker, F. \& Hurle, K. (2001) - Weed supression by release of isothiocyanates from turnip-rape mulch. Agronomy Journal, vol. 93, n. 1, p. 37-43. http://dx.doi.org/10.2134/agronj2001.93137x

Piña-Rodrigues, F.C.M. \& Lopes, B.M. (2001) - Potencial alelopático de Mimosa caesalpinaefolia Benth sobre sementes de Tabebuia alba (Cham.) Sandw. Floresta e Ambiente, vol. 8, n. 1, p. 130-136.

Reigosa, M.; Gomes, A.S.; Ferreira, A.G. \& Borghetti, F. (2013) - Allelopathic research in Brazil. Acta Botanica Brasilica, vol. 27, n. 4, p. 629-646. http://dx.doi.org/10.1590/S0102-33062013000400001

Rice, E.L. (1984) - Allelopathy. Academic Press.

Rizzardi, A.; Rizzardi, M.A.; Lamb, T.D. \& Johann, L.B. (2008) - Potencial alelopático de extratos aquosos de genótipos de canola sobre Bidens pilosa. Planta Daninha, vol. 26, n. 4, p. 717-724. http://dx.doi.org/10.1590/ S0100-83582008000400002

Rocha, S.; Ming, L.C. \& Marques, M. (2000) - Influência de cinco temperaturas de secagem no rendimento e composição do óleo essencial de citronela (Cymbopogon winterianus Jowitt). Revista Brasileira de Plantas Medicinais, vol. 3, n. 1, p. 73-78. 
Rodrigues, L.R.A.; Almeida, A.R.P. \& Rodrigues, T.J.D. (1993) - Alelopatia em forrageiras e pastagens. In: Simpósio sobre ecossistema de pastagens, 2., 1993, Jaboticabal. Anais. Jaboticabal: FUNEP, p. 100-129.

Rosa, D.M.; Fortes, A.M.T.; Palma, D.; Marques, D.S.; Corsato, J.M.; Leszczynski, R. \& Mauli, M.M. (2007) Efeito dos Extratos de Tabaco, Leucena e Sabugueiro sobre Germinação de Panicum maximum Jaqc. Revista Brasileira de Biociências, vol. 5, n. sup. 2, p. 444-446.

Sahpaz, S.; Bories, C.H.; Loiseau, P.M.; Cortes, D., Hocquemiller, R.; Laurens, A. \& Cave, A. (1994) - Cytotoxic and antiparasitic activity from Annona senegalensis seeds. Planta Medica, vol. 60, n. 6, p.538-540. https://doi. org/10.1055/s-2006-959566

Shaw, W.C. (1982) - Integrated weed management systems technology for pest management. Weed Science, vol. 30, n. S1, p. 2-12.

Souza Filho, A.P.D.S.; Rodrigues, L.R.A. \& Rodrigues, T.J.D. (1997) - Efeitos do potencial alelopático de três leguminosas forrageiras sobre três invasoras de pastagens. Pesquisa Agropecuária Brasileira, vol. 32, n. 2, p. 165-170.

Souza Filho, A.P.D.S.; Vasconcelos, M.A.M.D.;Zoghbi, M.D.G.B. \& Cunha, R.L. (2009) -Efeitos potencialmente alelopáticos dos óleos essenciais de Piper hispidinervium C. DC. e Pogostemon heyneanus Benth sobre plantas daninhas. Acta Amazonica, vol. 39, n. 2, p.389-396. http://dx.doi.org/10.1590/50044-59672009000200018

Waller, G.R.; Feng, M.C. \& Fujii, Y. (1999) - Biochemical analysis of allelopathic compounds: plants, microorganisms, and soil secondary metabolites. In: Inderjit; Dakshini, K.M.M.; Foy, C.L. (Eds.) Principles and practices in plant ecology. CRC Press, Boca Raton, p. 75-98. 